\title{
Research on Sports Diplomacy Between China and Southeast Asia and South Asia under the New Situation
}

\author{
Youfeng Wang ${ }^{1}$ \\ ${ }^{1}$ Department of Physical Education, Oxbridge College, Kunming University of Science and \\ Technology, Kunming, Yunnan Province, China
}

Keywords: New Situation; Southeast Asia; South Asia; Sports; Diplomacy; Research.

\begin{abstract}
Sports diplomacy has many advantages, such as mass participation, social influence and so on. Strengthening the international sports exchanges between China and neighboring countries under the new situation will contribute to promoting and improving the development of competitive sports in China. It is also conducive to stimulating the development of the relevant sports industry, the national economy, the promotion of national political and diplomatic exchanges, the promotion of the good neighborly friendship between China and the countries around. To strengthen the international exchanges in sports with Southeast Asia and South Asia is necessary for China's comprehensive development. Currently, China has strong policy supporting, traditional sports projects, rich sports tourism resources and cultural resources. To strengthen the international sports diplomacy between China and neighboring countries under the new situation will contribute to promoting and improving the development of competitive sports in China, stimulating the relevant sports industry development, stimulating the national economy, promoting the national political and diplomatic diplomacy between countries and promoting good neighborly friendship [1]. However, China's sports diplomacy faces opportunities and challenges. For instance, the local traditional sports are not standardized and the competitive sports mechanism is not mature. This paper is based on the domestic and international exchanges in sports practice and the current situation. It explores into the significance and the current status of sports diplomacy between China and Southeast Asia, South Asia, puts forward the corresponding strategies to solve the possible problems and strives to promote China's sports diplomacy and makes contributions to the sports diplomacy between China and Southeast Asia and South Asia.
\end{abstract}

\section{The Significance of Sports Diplomacy Between China and Southeast Asia, South Asia under the New Situation}

To promote political and diplomatic diplomacy between countries and to promote good neighborly friendship between countries. Sports diplomacy has many advantages, such as mass participation, positive content, social influence and so on. It contributes to stimulating the development of the relevant sports industry, the national economy, the promotion of national political and diplomatic exchanges, the promotion of the good neighborly friendship between China and the countries around. Sports diplomacy is conducive to promoting the development of friendly and cooperative relations between countries, promoting the friendship between the various ethnic groups and promoting good neighborly friendship between countries [2]. For example, the famous "Ping-Pong diplomacy" breaks the two countries' awkward diplomacy situation and enhances the friendship between the two countries. Sports diplomacy and national diplomacy are complementary and inseparable. Good diplomatic environment at home and abroad is a prerequisite for the development of comprehensive national strength, as well as a guarantee for the smooth conduct of foreign diplomacy. On the other hand, good sports diplomacy will not only closely cooperate with the government, but also serve and promote the country's diplomacy. China adheres to the principle of "being partners with the neighbors and being kind to the neighbors" and keeps the harmonious relations with Southeast Asia, South Asia. In addition to the economic and trade diplomacy between the two countries, China also attaches great importance to the sports diplomacy [3]. International diplomacy in sports can not only promote positive economic ties between China and Southeast Asia, 
South Asia, but also enhance the friendship between neighbors and make the relations between different ethnic groups closer, promote the good neighborly and friendly relations between nations. We can not only promote the cooperation in sports activities and projects, but also pursuit the development with higher level and broader areas.

To expand the development of sports industry and to promote the national economy. Sports, as an important pillar industry, plays an irreplaceable role in China's economic development. Yunnan province in China, for example, has its unique advantages of sports diplomacy with Southeast Asia, South Asia [4]. In addition, Yunnan province is rich in sports tourism resources, such as the activity of Shangdaoshan in February; the Bai's horse race in March; the Water Splashing Festival in April; the Yao's worship and dance activity in May; the Hani antiphonal singing activities in June; the Yi's Torch Festival in July; the Achang's Dragon Playing in September; the Hui's Balm Gifting activity in gift; the Nu's Swing activity in the twelfth month of the lunar year. There are unique traditional sports activities in almost every month in Yunnan province's, which greatly boosting the sports tourism industry in Yunnan and greatly improves its economic level [5]. In addition to the development of traditional sports activities and rich tourism, Yunnan province conducts the sports diplomacy with Southeast Asia and South Asia, which is conducive to the organization of China's competitive sports, such as the Olympic Games and Asian Games and other sports activities. These not only bring good sports feast, but also make more the states and more people appreciate the sports events, which increases China's economic income and promotes the fast and steady development of its economy.

To promote the prosperity and progress of all ethnic cultures. Regardless of the country, the nationality, the race, the competitive sports attract anyone who loves sports and has sports spirit to gather together and participate in sports. Indeed, in the international interactive activities, sports are seldom influenced by the regional, national, ethnic, language and other factors. People with different races, different nations, different religious beliefs can come together to exchange ideas and discuss techniques, which enhances the mutual understanding and friendship. To strengthen the international diplomacy in sports between China and Southeast Asia, South Asia is not only conducive to political stability between nations and the development of the economy, but also conducive to the promotion of different ethnic culture's prosperity and progress [6]. In the continuous evolution and development of human beings, due to the different living environment and living habits, different ethnic groups have different behaviors and different movement forms. Each has its own charm and its own characteristics. For example, adjacent to Southeast Asia and South Asia, Yunnan province has rich ethnic traditional sports activities, such as Water Splashing Festival, horse racing, Dragon Boat Race. Southeast Asia and South Asia is popular for their kick boxing and boxing and other sports activities. Due to the sports diplomacy between China and Southeast Asia, South Asia, China's Water Splashing Festival and horse racing have been popular in Southeast Asia and South Asia. Southeast Asia and South Asia's boxing and kick boxing are also imperceptibly passed into China. To certain extent, the sports diplomacy between countries promotes the progress of the countries and the external activities between countries, promote the nations' prosperity [7]. We believe that as long as we adhere to the principle of "promoting the relations between countries through the sports", we will promote the culture.

To promote the development and improvement of China's competitive sports. Sports not only affects people's physical quality and the construction of socialist spiritual civilization, but also affects the development and improvement of competitive sports. Under the efforts of the Chinese government and the athletes, our competitive sports have made certain progress and great achievements. In 2008, China successfully held the Olympic Games, which shows the charm of a sports country. Since then, China has hosted many international large-scale sports events. Not only the sports fans can make a feast for the eyes, but also the sports industry in China has been fully developed. With the trend of economy and globalization, it is becoming more and more obvious to strengthen the diplomacy with sports in Southeast Asia and South Asia. In Southeast Asia, South Asia and other regions, athletics, boxing, martial arts and other sports events are worth learning. The diplomacy and exchange between countries make the sports culture change from the folk cooperation to "folk cooperation + official exchanges" in the new situation of diplomacy [8]. With the deepening 
of exchanges and cooperation, we even have the opportunity to work together to undertake larger and more international sports event, promote the communications and further promote the development and improvement of competitive sports.

\section{The Advantages and Conditions of China's Sports Diplomacy with Southeast Asia, South Asia under the New Situation}

Abundant sports tourism resources and sports culture resources. Under the new situation, we should enhance the sports diplomacy between China and Southeast Asia and South Asia. Our country has certain advantages and conditions in many aspects. First of all, China has abundant sports tourism resources and sports cultural resources. With a vast territory, China not only has rich spiritual and cultural resources, but also has many sports tourism resources and sports cultural resources. For example, in Yunnan province adjacent to Southeast Asia and South Asia, there are a variety of traditional ethnic sports activities such as race, Dragon Boat Race. To the north of China's Yangtze River, the athletics, the ball games are the main sports programs. In the coastal area of our country, the boating, swimming are the main sports programs. In China's inland areas, the football, basketball and table tennis are the main sports programs [9]. The rich sports tourism resources continually attract the international friends to visit our country, even personally involved in the sports. These all greatly make the publicity of China's sports and strengthen the international sports diplomacy between China and our neighboring countries.

On the other hand, China's sports culture has a long history. Almost every traditional sports activity has a good sports legend. For instance, the famous Dai Water Splashing Festival is to commemorate a brave girl who fight to protect the people. The Dai people hold activities to express their gratitude and blessings of nation. Other rich sports tourism resources and sports cultural resources also make our country's sports activities full of fascinating charm, which is more conducive to Southeast Asia, South Asia and the sports diplomacy.

Superior geographical position is conducive to the development of sports activities in Southeast Asia and South Asia. In order to smoothly promote the sports diplomacy between our country and Southeast Asia, South Asia, in addition to the rich sports tourism resources and sports culture resources, the good geographical location is also required. China's Yunnan province is located in China's border with the South Asian subcontinent, being contiguous to Vietnam, Laos, Burma and being near to Thailand, Kampuchea, India, Bangladesh and other neighboring countries. Under the impetus of reform and opening up, Yunnan has initially built a comprehensive, multi-level opening up pattern with the target market of Southeast Asia [10]. In addition, the famous Lancang River-Mekong River basin is connected to the Yunnan province of China and Southeast Asia, South Asia and other regions. For a long time, Chinese and Indochina countries keep close sports cultural exchanges, greatly promote the harmonious development of our country and the regional countries. With the exchanges and cooperation more than half a century, it effectively promotes the development of our country's sports activities and those of Southeast Asia, South Asia and other areas.

\section{The Problems Faced by China in the Sports Diplomacy with Southeast Asia, South Asia under the New Situation}

The local traditional national sports are not standardized and the competitive sports have many deficiencies. Our country has attached great importance to the development of sports activities. However, compared with developed countries, our country started later. In addition to table tennis which is also called "national ball" and is the best in the world, some sports such as football, has below the average level [11]. On the other hand, due to the limitations of the physical quality of Asians, many sports have not been developed. To strengthen the sports diplomacy with Southeast Asia, South Asia and other regions, we should take the essence and discard the dross, learn from each other, continuously improve the methods of sports training, continuously improve the macro and details of sports and promote the development of competitive sports in China. For example, in the 
international sports diplomacy with Southeast Asia, South Asia, we can hold the sports events to mutually support each other, continuously improve China's competitive sports arena running level. We can also hire foreign coaches to let the excellent foreign coaches use their national sports strengths to help us to continuously improve the level of sports.

\section{The Relevant Strategies of Sports Diplomacy Between China and Southeast Asia, South Asia in the New Situation}

The government and the relevant departments should play a leading role in promoting sports to promote the sports diplomacy and cooperation. The sports activities with wide participation, positive content, social impact and other features are not only conducive to improving the national physical quality and spirit, but also having important significance on China's political, economic, cultural etc. The construction of physical education cannot be separated from the support of strong government support. Under the new situation, our country should strengthen the sports diplomacy with Southeast Asia and South Asia. First of all, it is necessary for the government and the relevant departments to play a leading role. They should set a good example, carrying out foreign relations strategy of sports in China, standardizing the sports processes, improving China's competitive sports activities level, enhancing the sports diplomacy activities with Southeast Asia, South Asia and other regions.

To increase investment and to strengthen the construction of sports infrastructure. The construction of physical education cannot be separated from the encouragement of the strong national policy. In order to well develop the sports industry, it is necessary to provide the strong financial support and other materials. In order to further standardize the development of sports activities, the relevant government departments should correct their attitude, realize the seriousness of the situation and the importance of sports development, give the appropriate encouragement, increase the financial support, equipment support, human resources support and investment and strengthen the construction of sports infrastructure.

To promote sports diplomacy mechanism and normalization. In the new period, we should strengthen the sports diplomacy in Southeast Asia, South Asia, follow the current situation, make clear the situation and diversely develop the sports diplomacy. We should regard "to adhere to strengthen the sports diplomacy with foreign countries and to achieve win-win cooperation" as the diplomacy standard, broaden the way of foreign exchanges and promote the institutionalization of sports competition and normalization [12]. At the same time, we should gradually enhance the physical quality of the athletes, further improve the infrastructure construction, improve the sports coaches' comprehensive unremitting knowledge, continue to accumulate the sports skills, extensively promote the sports, expand the depth and breadth of sports exchanges, promote the mechanisms and normalization of sports diplomacy.

\section{Conclusions}

Sports diplomacy has many advantages, such as mass participation, social influence and so on. It is one of the most important ways for a country to communicate with the others. The development of the sports industry is on behalf of the national prosperity, as well as an important embodiment of the national political stability, cultural prosperity, health. To strengthen the international exchanges in sports with Southeast Asia and South Asia is necessary for China's comprehensive development. Currently, China has strong policy supporting, traditional sports projects, rich sports tourism resources and cultural resources. This is the best time to strengthen the sports diplomacy relation between China and the Southeast Asia and South Asia. [13] Strengthening the international sports exchanges between China and neighboring countries under the new situation will contribute to promoting and improving the development of competitive sports in China. It is also conducive to stimulating the development of the relevant sports industry, the national economy, the promotion of national political and diplomatic exchanges, the promotion of the good neighborly friendship between China and the countries around. However, China's sports diplomacy faces opportunities and 
challenges. For instance, the local traditional sports are not standardized and the competitive sports mechanism is not mature. While facing the problems, the government and the relevant departments should play a leading role in promoting foreign sports and cooperation, to increase investment, to strengthen the construction of sports infrastructure; to promote the competitive sports diplomacy mechanism and normalization, to adopt the various measures to vigorously promote the sports diplomacy activities.

\section{References}

[1] Ming-ming Xu. Study on the History of Sports Diplomacy of New China from 1949 to 1965 [A]. Annual Meeting of the National Sports and Social Sciences in 2012: Exploration into the Ways to Change the Sports Development [C]. 2012.

[2] Ting-kui Li, Zhong-min Liu \& Kai Fu. Discuss on the Re-arrangement and Orientation of Sports Cultural Diplomacy in China's Cultural Diplomacy From the Current Situation of Africa [A]. Proceedings of the Ninth National Sports Science Conference in 2011 (1) [C]. 2011.

[3] Da-wei Yu \& Xiao-yi Zhang. The Establishment of International Trust Mechanism and the Mission of Chinese Sports Diplomacy [A]. Proceedings of the Ninth National Sports Science Conference in 2011 (1) [C]. 2011.

[4] Gao-shan Wang \& Xiao-hong Kong. On the Foreign Policy of Sports in China: An Interpretation based on Concept [J]. Brand. 2013 (03).

[5] Run-bin Wang \& Sheng-jun Zhang. Chinese Sports Diplomacy: Functions, Problems and Tasks [J]. Public Diplomacy Quarterly. 2012 (03).

[6] Yong-gang Jin. Also about Sports Diplomacy [J]. Journal of Bohai University (Philosophy and Social Science Edition). 2014 (01).

[7] Fu-gang Wang. The Applications of Sports Diplomacy [J]. LIAONING GUANGBO DIANSHI DAXUE XUEBAO. 2013 (04).

[8] Xin-ying Zhang. New Comment on China Sports Diplomacy [J]. Technique of Practical Fighting. 2012 (08).

[9] Ming-ze Liu, Ling Bai \& Ai-hui Sun. On Chinese Sports Diplomacy from the Perspective of Soft Power [J]. Journal of Education Institute of Jilin Province. 2012 (02).

[10] Shi-yang Chen, Chi Zhang \& Li-yuan Zhang. Further Discussion of the Sports Diplomacy [J]. Journal of Hebei Institute of Physical Education. 2015 (04).

[11] San-ai Jia, Hai-ying Pan \& Jun-meng Chen. The Function and Influence of Sports Diplomacy in China [J]. Contemporary Sports Technology. 2013 (23).

[12] You-feng Wang. Discussion on the Ways and Strategies of Enhancing the Soft Power of National Traditional Sports Culture in Yunnan [J]. Sports. 2015 (17).

[13] Wei-hua Zhao \& Dong-li Jin. The Role and Functions of Yunnan Province in the Construction of New Diplomatic Relations with Neighboring Countries [J]. The Journal of Yunnan Administration College. 2014 (06). 